\title{
NOX5 is expressed aberrantly but not a critical pathogenetic gene in Hirschsprung disease
}

Jing Wang ${ }^{1 \dagger}$, Jun Xiao ${ }^{1 \dagger}$, Xinyao Meng ${ }^{1}$, Xufeng $\mathrm{Chu}^{2}$, Di Di Zhuansun ${ }^{1}$, Bo Xiong ${ }^{2^{*}}$ and Jiexiong Feng ${ }^{1 *}$

\begin{abstract}
Background: Hirschsprung disease (HSCR) is a congenital disorder characterized by the absence of intramural ganglion cells in the distal gastrointestinal tract (Gl), which results in tonic contraction of the aganglionic gut segment and functional intestinal obstruction. Recent studies have suggested NADPH oxidase 5 (NOX5) as a candidate risk gene for HSCR. In this study, we examined the function of NOX5 to verify its role in the development of the enteric nervous system (ENS).

Methods: HSCR tissue specimens $(n=10)$ were collected at the time of pull-through surgery and control specimens $(n=10)$ were obtained at the time of colostomy closure in patients. The NOX5 expression in aganglionic and ganglionic segments of HSCR colon and normal colon were analyzed by immunohistochemistry (IHC), western blot and real-time quantitative PCR (qPCR). The gene expression levels and spatiotemporal expression spectrum of NOX5 in different development stages of zebrafish embryo were determined using qPCR and in-situ hybridization (ISH). The enteric nervous system in NOX5 Morpholino (MO) knockdown and wild type (WT) zebrafish embryo was analyzed by whole-mount immunofluorescence (IF). Intestinal transit assay was performed to analyze the gastrointestinal motility in NOX5 knockdown and control larvae.
\end{abstract}

Results: NOX5 is strongly expressed in the ganglion cells in the proximal segment of HSCR colons and all segments of normal colons. Moreover, the expression of NOX5 is markedly decreased in the aganglionic segment of HSCR colon compared to the ganglionic segment. In zebrafish, NOX5 mRNA level is the highest in the one cell stage embryos and it is decreased overtime with the development of the embryos. Interestingly, the expression of NOX5 appears to be enriched in the nervous system. However, the number of neurons in the Gl tract and the Gl motility were not affected upon NOX5 knockdown.

Conclusions: Our study shows that NOX5 markedly decreased in the aganglionic segment of HSCR but didn't involve in the ENS development of zebrafish. It implies that absence of intestinal ganglion cells may lead to downregulation of NOX5.

Keywords: Hirschsprung disease, NOX5, Enteric nervous system, Zebrafish, Embryo

\footnotetext{
*Correspondence: bxiong@hust.edu.cn; jiexiongfeng@126.com

†Jing Wang and Jun Xiao contributed equally to this work.

${ }^{2}$ Department of Forensic Medicine, Tongji Medical College, Huazhong

University of Science and Technology, Hangkong road, Baofeng street,

Qiaokou district, Wuhan 430030, China

'Department of Pediatric Surgery, Tongji Hospital, Tongji Medical College,

Huazhong University of Science and Technology, 1095 Jiefang Ave, Wuhan

430030, China
}

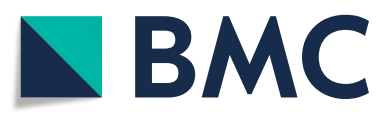

(c) The Author(s). 2021 Open Access This article is licensed under a Creative Commons Attribution 4.0 International License, which permits use, sharing, adaptation, distribution and reproduction in any medium or format, as long as you give appropriate credit to the original author(s) and the source, provide a link to the Creative Commons licence, and indicate if changes were made. The images or other third party material in this article are included in the article's Creative Commons licence, unless indicated otherwise in a credit line to the material. If material is not included in the article's Creative Commons licence and your intended use is not permitted by statutory regulation or exceeds the permitted use, you will need to obtain permission directly from the copyright holder. To view a copy of this licence, visit http://creativecommons.org/licenses/by/4.0/ The Creative Commons Public Domain Dedication waiver (http://creativecommons.org/publicdomain/zero/1.0/) applies to the data made available in this article, unless otherwise stated in a credit line to the data. 


\section{Background}

HSCR is caused by failures of the proliferation, differentiation or migration of enteric neural crest cells (ENCCs), resulting in aganglionosis of the distal part of the gastrointestinal tract [1]. According to the length of the aganglionic segment, it can be further classified as short segment HSCR, long segment HSCR, total colonic aganglionosis (TCA) and total intestinal aganglionosis [2]. The aganglionosis then leads to severe intestinal obstruction, which requires surgical removal of the aganglionic segment to treat [3].

HSCR is a highly heritable disorder (OMIM 142623). Familial and syndromic HSCR show a Mendelian pattern of inheritance. However, the etiology of the sporadic HSCR seems to be intricate, presenting a nonMendelian type inheritance and involving many genetic and environmental factors [4]. So far, more than 20 HSCR susceptibility genes have been found to be associated with the development of ENS and most of them were involved in the RET (encoding a tyrosine kinase) and EDNRB signaling pathways $[5,6]$. The RET/GDNF/ GFRA1 signaling pathway and the Endothelin 3Endothelin Receptor B signaling pathway are the most common known pathways involved in HSCR development. Besides, transcription factors like SOX10, PHOX2B, ZEB2 etc. are also playing important roles in the development of ENS [4]. Recent studies have also demonstrated the association between SEMA3 and HSCR, which was applicable to specific ethnic groups [7-9]. However, only approximately $30 \%$ of all HSCR patients carry mutations in these genes, suggesting that there must be many other genes participating in the etiology of HSCR.

In the last few years, lots of novel susceptibility genes and variants for HSCR were identify by genome-wide association studies (GWAS) [10, 11]. In a recent GWAS of HSCR, NOX5 was identified as a susceptibility gene [12]. Furthermore, a follow-up association analysis between NOX5 polymorphisms and risk of HSCR indicated that several hereditary variants in NOX5 were significantly associated with HSCR susceptibility [13].

NOX5, which belongs to the NADPH oxidase family, is one of the major producers of reactive oxygen species (ROS) in mammalian cells [14]. NADPH oxidases are membrane proteins that generate superoxides, particularly ROS, which have been shown to be participated in various signaling cascades and cellular processes including proliferation, apoptosis and migration. Dysfunction of the NOX enzyme could lead to abnormal levels of ROS that may cause diseases [15]. Previous studies have demonstrated that NOX5 is involved in various pathological conditions, including cancer, cardiovascular and atherosclerotic diseases [16-18]. However, no in vivo or in vitro study has provided immediate evidence that
NOX5 is required for the development or function of the ENS. In this study, we aimed to test whether loss of NOX5 would lead to the disruption of the biological processes of enteric neurons using zebrafish models.

\section{Methods}

\section{Tissue collection}

This study complied with the Declaration of Helsinki and was approved by the Review Board of Ethics Committee of Tongji Hospital. Consent forms were sent to patients at the age between 0 and 5 years and signed by their legal custodians. Full-length resected bowel specimens obtained during pull-through operations for HSCR were collected from ten patients. Three of these patients had a history of preoperative HAEC. Resected tissues included aganglionic and ganglionic segments. Ganglionic segments were taken from the most proximal margin of the resected pull-through specimen while aganglionic segments were taken from the most distal margin of the resected specimen. Control group of specimens were obtained from imperforate anus patients after colostomy $(n=10)$. Tissue specimens were stored in three ways following collection. One portion of each specimen was fixed in formalin at room temperature, for paraffin embedding and immunochemistry. A second portion was snap frozen in a mold containing optimal cutting temperature medium and stored at $-80^{\circ} \mathrm{C}$ for immunofluorescence. The remaining specimen was stored at $80^{\circ} \mathrm{C}$ for protein or total RNA extraction.

\section{Protein extraction and Western blot}

Each protein sample of zebrafish was extracted from 30 embryos. The western blot was then performed as previously described [19]. The rabbit anti-NOX5 antibody (Abcam, Cambridge, UK, ab191010) was used at a concentration of 1:1000. The rabbit anti-beta III Tubulin (Tuj1) antibody (Abcam, Cambridge, UK, ab18207) was used at a concentration of 1:1000. The HRP linked goat anti-rabbit secondary antibody (Abcam, Cambridge, UK) was used at 1:10,000 dilution. Beta actin (dilution 1: 1000, Abcam, Cambridge, UK) was used as the loading control. The relative level of protein was determined by the normalized density of each band in the western blot using the ImageJ software.

\section{Immunohistochemistry}

Sections $(4 \mu \mathrm{m})$ on silane-coated slides (Muto Pure Chemicals Co., Ltd., Tokyo, Japan) were deparaffinized in xylene and dehydrated in solutions with decreasing concentrations of ethanol. After rehydration and blocking of endogenous peroxidase activity with $3 \%$ of hydrogen peroxide for $10 \mathrm{~min}$, heat-induced epitope retrieval was performed for $20 \mathrm{~min}$ in $0.01 \mathrm{M}$ citrate buffer $(\mathrm{pH}$ 6.0) in a pressure cooker. Primary antibody for NOX5 
was used at 1:100 and incubated for $30 \mathrm{~min}$. After washing and incubation with EnVision ${ }^{\text {tw }}$ for 30 min, color products were developed using the Liquid $\mathrm{DAB}+$ as chromogen. The sections were counterstained with hematoxylin before dehydration and coverslipping. Slides processed without primary antibody were prepared as negative controls.

\section{Zebrafish housing/breeding}

The zebrafish protocols were approved by the Institutional Animal Care and Use Committee at Tongji Hospital. The $A B$ strain zebrafish were maintained according to standard procedures [20]. Embryos were raised in $\mathrm{E} 3$ medium at $28.5^{\circ} \mathrm{C}$ and staged as previously described [21]. $0.003 \% \mathrm{~N}$-phenylthiourea was added to E3 medium to inhibit melanization.

\section{Real-time quantitative PCR}

Total RNA was isolated from 0.2, 6, 12, 24, 48, and 72hpf embryos and colon tissues with TRIzol reagent (Life Technologies, Carlsbad, CA). qPCR and data analysis were performed using LightCycler96 (Roche Diagnostics). Relative expression levels were calculated using $\beta$-actin as internal reference. The experiments were repeated three times with biological replicates. Zebrafish primers (NOX5 primer: Forward, 5' - ATT CACGGCAC T GAAACGGA-3', Reverse, 5'-GGAGCTCCGCATGA TT TACCT A-3'; $\beta$-actin primer: Forward, 5 '-CGAGCT GTCTTCCCATCCA-3', Reverse, 5' -TCACC AACGTA GCTG TCTTTCTG-3'). Human primers (Tuj1 primer: Forward, 5'- GGA AGAGGGCGAGATGTACG-3', Reverse, 5' - GGGTTTAGACACTGCTGGCT-3'; $\beta$ actin primer: Forward, $5^{\prime}$ - CCTTCCTGGGCATGGAGT C-3', Reverse, 5' - TGA TCTTCATTGTGCTGGGTG3'. NOX5 primer: Forward, 5'-CCAGAAAGTGGCTG CTGAGA-3', Reverse, 5' -AGCTTGGAGAGGTGAGGC TA-3).

\section{Whole-mount in situ hybridization}

The 0.2, 6, 12, 48hpf Embryos ( $n=15$ for each phase) were collected and processed for whole-mount ISH as previously described [22].

A 735-bp fragment of the NOX5 cDNA was amplified using the following primers: Forward: 5 '-CGGAGGTC TCTGGATCATGC-3', Reverse: 5'-ATGTGCAGCC ACAA CGTTTC-3'. A T7 promoter was added to the reverse primer. The ISH probe was then generated by in vitro transcription using T7 RNA polymerase.

\section{Microinjection of morpholino antisense oligonucleotides} NOX5 knockdown experiments using MO were carried out as previously described [23]. ATG morpholino antisense oligonucleotides targeting NOX5 were designed and synthesized as follows: NOX5-MO 5'-CGGGTGTC
ATCATCCAGACTCAT-3', a 5-nucleotide-mismatch morpholino was used as control: 5' - CGGcTGaCtTgATCCAcAC TCAT - 3'. Zebrafish embryos were injected with $5 \mathrm{ng}$ of the $\mathrm{MO}$ at the one cell stage. The knockdown efficiency was validated using western blot.

\section{Whole-mount Immunofluorescent staining}

Whole-mount Immunofluorescent staining with the anti-HuC/D antibody (A-21271, Life Technologies) was performed to examine the enteric neurons along the GI tract. The $5 \mathrm{dpf}$ embryos $(n=20)$ were collected and fixed with $4 \%$ PFA overnight. The embryos were washed with PBS. After incubation in blocking solution ( $2 \%$ goat serum, $2 \mathrm{mg} / \mathrm{ml}$ BSA in $1 \times \mathrm{PBS}$ ) for $1 \mathrm{~h}$ at room temperature, embryos were incubated with the anti$\mathrm{HuC} / \mathrm{D}$ antibody (1500) in blocking solution overnight at $4{ }^{\circ} \mathrm{C}$. After two washes in PBS for $10 \mathrm{~min}$ each time, embryos were incubated in the secondary antibody solution, 1: 1000 Alexa Fluor rabbit anti-mouse IgG (A11001, Life Technologies) in PBS, for $1 \mathrm{~h}$ at room temperature. Finally, the images were acquired using LSM 800 confocal microscope (Zeiss, Germany). The number of $\mathrm{HuC} / \mathrm{D}$-positive cells in the gut was then quantified using ImageJ. All of the experiments were repeated for three times.

\section{Zebrafish intestinal transit assay}

The tracer was prepared by mixing $100 \mathrm{mg}$ of egg yolk, $150 \mu \mathrm{L}$ of yellow-green fluorescent 2.0 -um polystyrene microspheres (Invitrogen, Carlsbad, CA, USA) and $50 \mu \mathrm{L}$ of deionized water as previously described [24]. For $7 \mathrm{dpf}$ zebrafish larvae $(n=65$ for Control, $n=75$ for NOX5Mo), approximately $2 \mathrm{mg}$ of tracer powder was administered per Petri dish in the morning. After 3, 6, and $9 \mathrm{~h}$, the larvae were anaesthetized by $0.2 \%$. tricaine (Sigma, St Louis, MO, USA) and imaged using a fluorescent dissecting microscope (Axio Zoom.V16, Zeiss, Germany). For scoring the transit efficiency, the zebrafish intestine was artificially divided into four zones according to anatomical landmarks and the larvae was grouped based on the anterior extent of the tracer.

\section{Statistical analysis}

The embryos were selected by Simple random sampling. Data were analyzed using the GraphPad Prism software package (version 5; GraphPad Software Inc., La Jolla, CA, USA) and are presented as the mean \pm standard error of the mean. Differences between two groups were analyzed using an unpaired t-test with Welch's correction. Analysis of variance (ANOVA) was used to compare data of more than two groups. Pearson's chi-square tests were used to assess the difference between $7 \mathrm{dpf}$ wild-type and NOX5-MO group transit profiles at different time points. The experiments and data analyzing 
were finished by different researchers. The analyst didn't know the grouping scheme in advance.

\section{Results}

NOX5 is located in the enteric neuron membrane

We first performed western blots and qPCR of NOX5 in the aganglionic segments and the ganglionic segments in 10 patients with HSCR and 10 normal colon samples. The results shown that NOX5 is indeed expressed in the colon. The ganglionic segments in HSCR patients and imperforate anus patients had a similar expression level of NOX5. However, the expression level of NOX5 in the aganglionic segments were markedly decreased (Figs. 1 and 2). Besides, the expression level of NOX5 is similar to Tuj1, which is a neuron specific marker in ENS. Next, we performed IHC and HE staining to examine the expression profile of NOX5 in the colon. NOX5 expression was observed in the ganglion cells in the myenteric and submucosa plexus of both the HSCR and control colons. However, NOX5 is hardly expressed in aganglionic segments (Fig. 3). Collectively, these data indicated that NOX5 is highly expressed in the ganglionic neurons of the colon, suggesting that it may play certain roles in these cells.

\section{Expression pattern of NOX5 in zebrafish embryos}

To analyze the function of NOX5 in vivo, we chose to use zebrafish as a model system. We performed ISH to determine the NOX5 expression pattern in different stages $(0.2,6,12,24,48,72 \mathrm{hpf})$ of zebrafish embryos. NOX5 started to express at 1-cell stage and is uniformly expressed pattern during the early stages of embryonic development (Fig. 4 a-c). After 24hpf, it is mainly expressed in the central nervous system, which is the origin of enteric neurons (Fig. 4 d-e). In addition, to qualify the relative level of NOX5 in different stages, we performed qPCR analyses and revealed that NOX5 expression is the highest in the one-cell stage and is decreased in the following stages until reaching plateau at around $48 \mathrm{hpf}$ to $72 \mathrm{hpf}$ (Fig. 5). Since the zebrafish enteric neurons are differentiated and migrated to their final location within the first 5 days of embryonic development, our data indicate that NOX5 is indeed expressed during the period of enteric neuron development.

\section{NOX5 is not required for zebrafish ENS development}

To test whether zebrafish ENS development require NOX5, we designed a MO to knockdown NOX5 expression level. Upon injection of $5 \mathrm{ng} N O X 5-\mathrm{MO}$ at one cell stage, the protein levels of NOX5 were significantly reduced until 5dpf (Fig SF1). We then used HuC/D immunofluorescence staining to detect the enteric neurons in $5 \mathrm{dpf}$ embryos. The results showed that the number of enteric neurons in NOX5 morphants are not significantly altered compare to controls (Fig. 6a-c). Moreover, the gut morphology was indistinguishable between the morphants and the controls. Thus, our data indicate that NOX5 is dispensable for enteric neuron system development in zebrafish.

\section{Gl transit function is not affected by NOX5 knockdown}

We further tested whether NOX5 is required for GI transit function by feeding larvae fluorescent microspheres in an emulsion of egg yolk and examining the microsphere transit through the GI at various time points. Upon feeding, both the control and NOX5 knockdown group larvae were anaesthetized and photographed at 3, 6 and $9 \mathrm{~h}$. For quantification, we divided the whole GI into four zones and calculated the number of larvae with the tracer in each zones (Fig. 7a). Representative images of the tracer location in controls and morphants at different time points

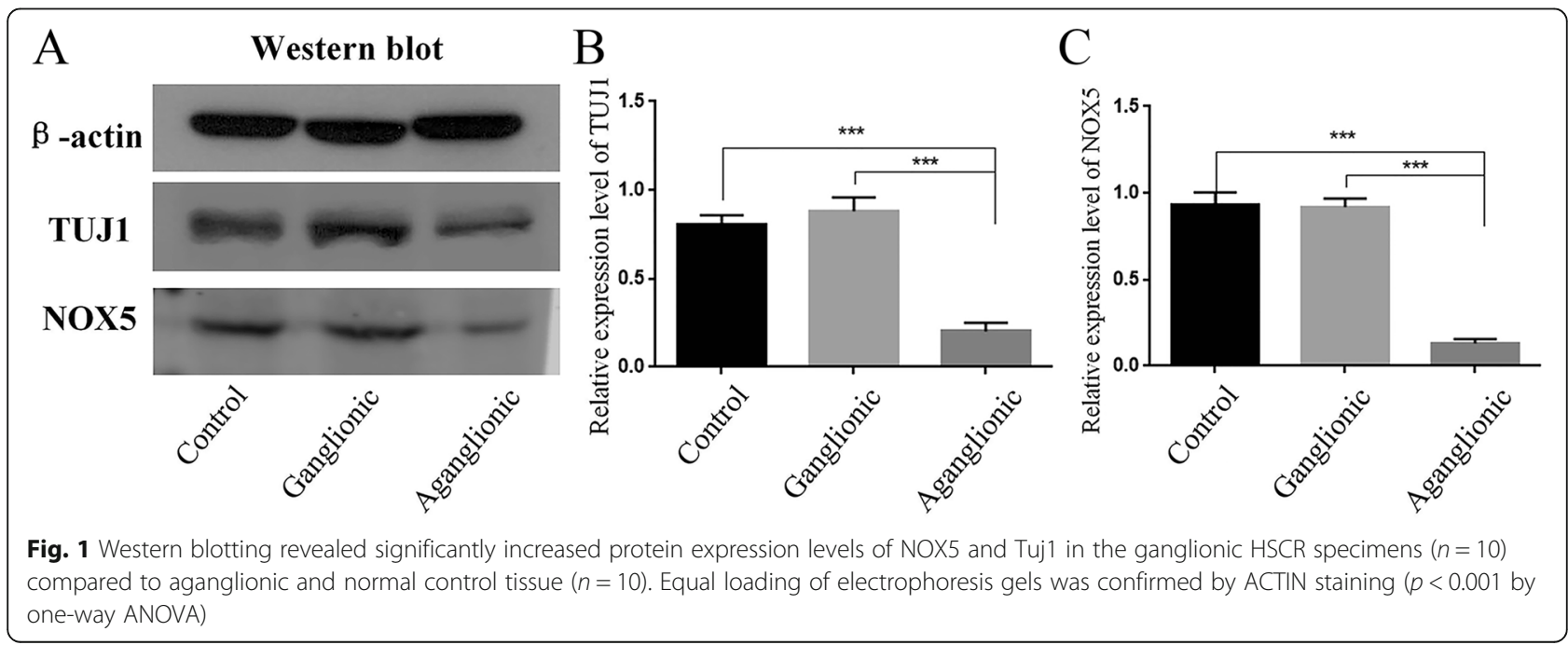



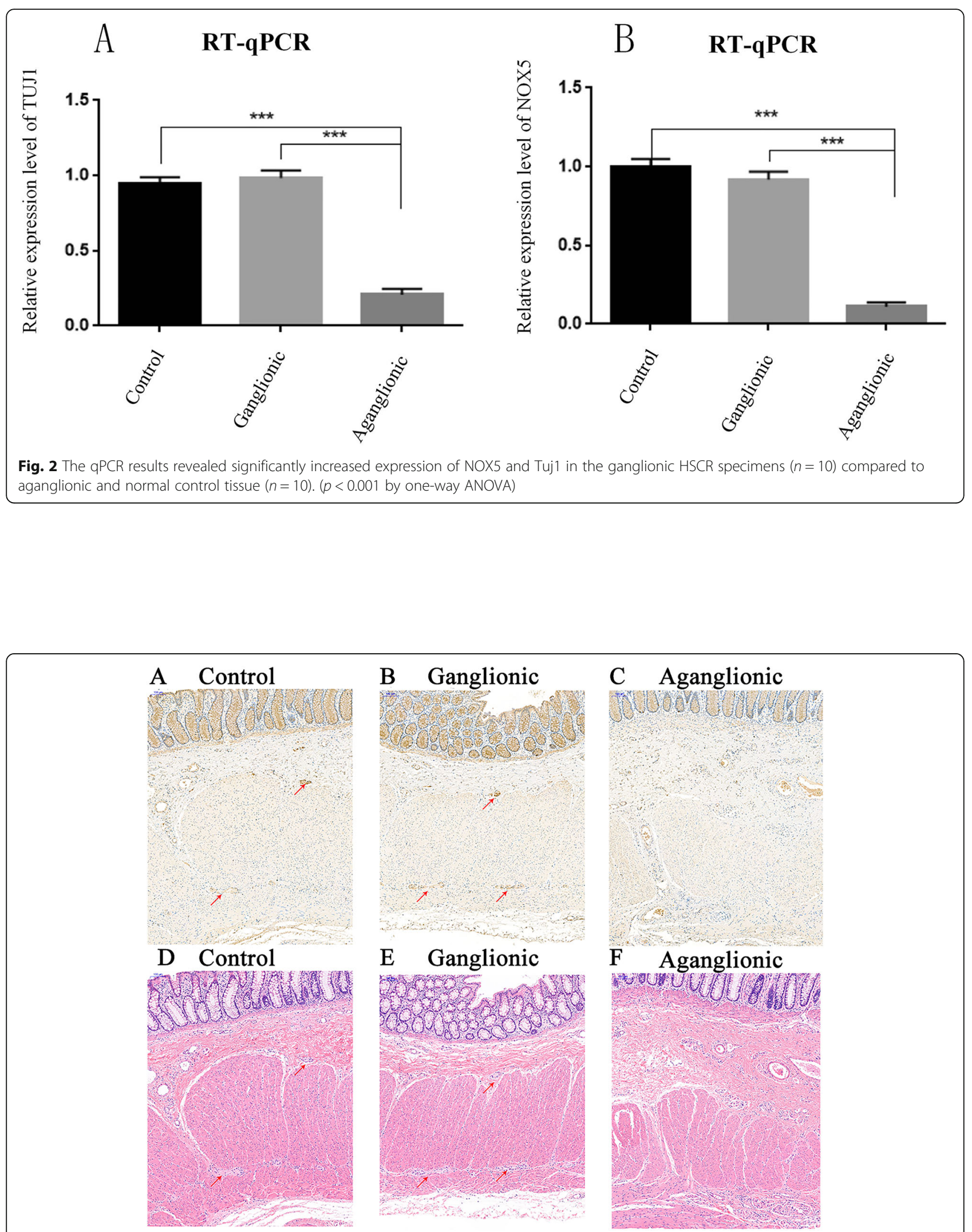

Fig. 3 NOX5 antibodies positively stained ganglion cells (arrows) in the submucosal and myenteric plexus of the ganglionic (a, $\mathbf{d}, \times 100)$ and normal colon $(\mathbf{c}, \mathbf{f}, \times 100)$ but not aganglionic colon $(\mathbf{b}, \mathbf{e}, \times 100)$. Each ISH section have a correspondent HE staining slide 


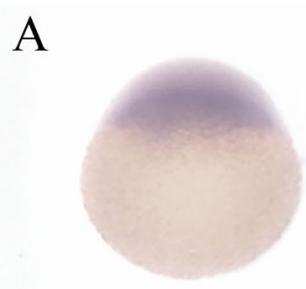

$0.2 \mathrm{~h}$
B

$\mathrm{D}$

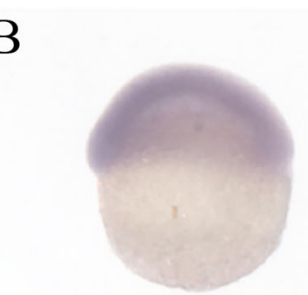

$6 \mathrm{~h}$
C

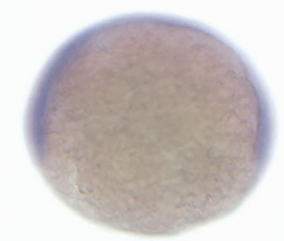

$12 \mathrm{~h}$

$\mathrm{E}$

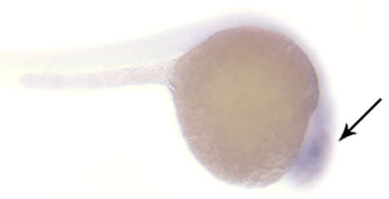

$24 \mathrm{~h}$

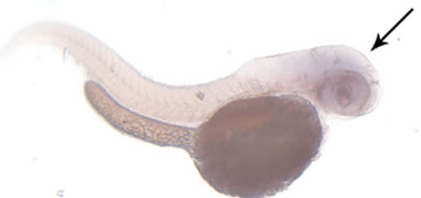

$48 \mathrm{~h}$

Fig. 4 Broad NOX5 expression through the first 2 days of development. a-e: 0.2, 6, 12, 24, and 48 hpf. d-e: Lateral views of whole-mount ISH embryos probed with NOX5 antisense show a relative specific positive expression in central nervous system

are displayed in Fig. 7b. There is no significant difference of the tracer patterns between the two groups of embryos (Fig. 7c, 3 h, $p=0.32,6$ h, $p=0.49,9$ h, $P=0.59$ ). These data suggested that NOX5 is not required for ENS function or GI transit in zebrafish embryos.

\section{Discussion}

HSCR is a highly heritable disorder [25]. Previously, a genome-wide association study (GWAS) with 123 sporadic HSCR patients and 432 unaffected controls identified NOX5 as a new susceptibility gene for HSCR [12]. Furthermore, an association analysis between NOX5 polymorphisms and risk of HSCR in 187 patients and 283 unaffected controls showed that the genetic variants in NOX5 were significantly associated with HSCR susceptibility, particularly for the L-HSCR and TCA subtypes [13]. Encouraged by these findings, we embarked on elucidating NOX5 function in ENS.

NADPH oxidases (NOX), comprising seven family members (NOX1-NOX5 and dual oxidase 1 and 2), are the major producers of reactive oxygen species in mammalian cells. NOX5 was first reported in 2001 based on a blast search using the C-terminus of gp91 ${ }^{\text {phox }}$ as bait to identify novel transcripts [26]. The exact

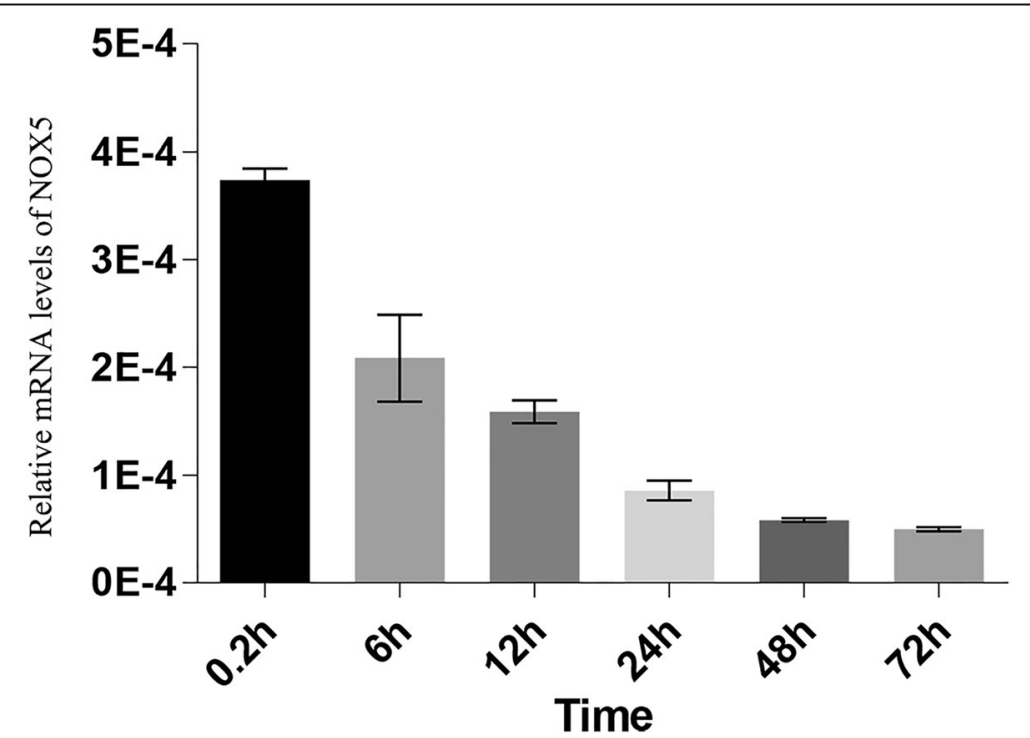

Fig. 5 NOX5 expressed during early zebrafish development. Relative mRNA levels of NOX5 derived via quantitative PCR normalized to ACTIN. N=6 for each data point 

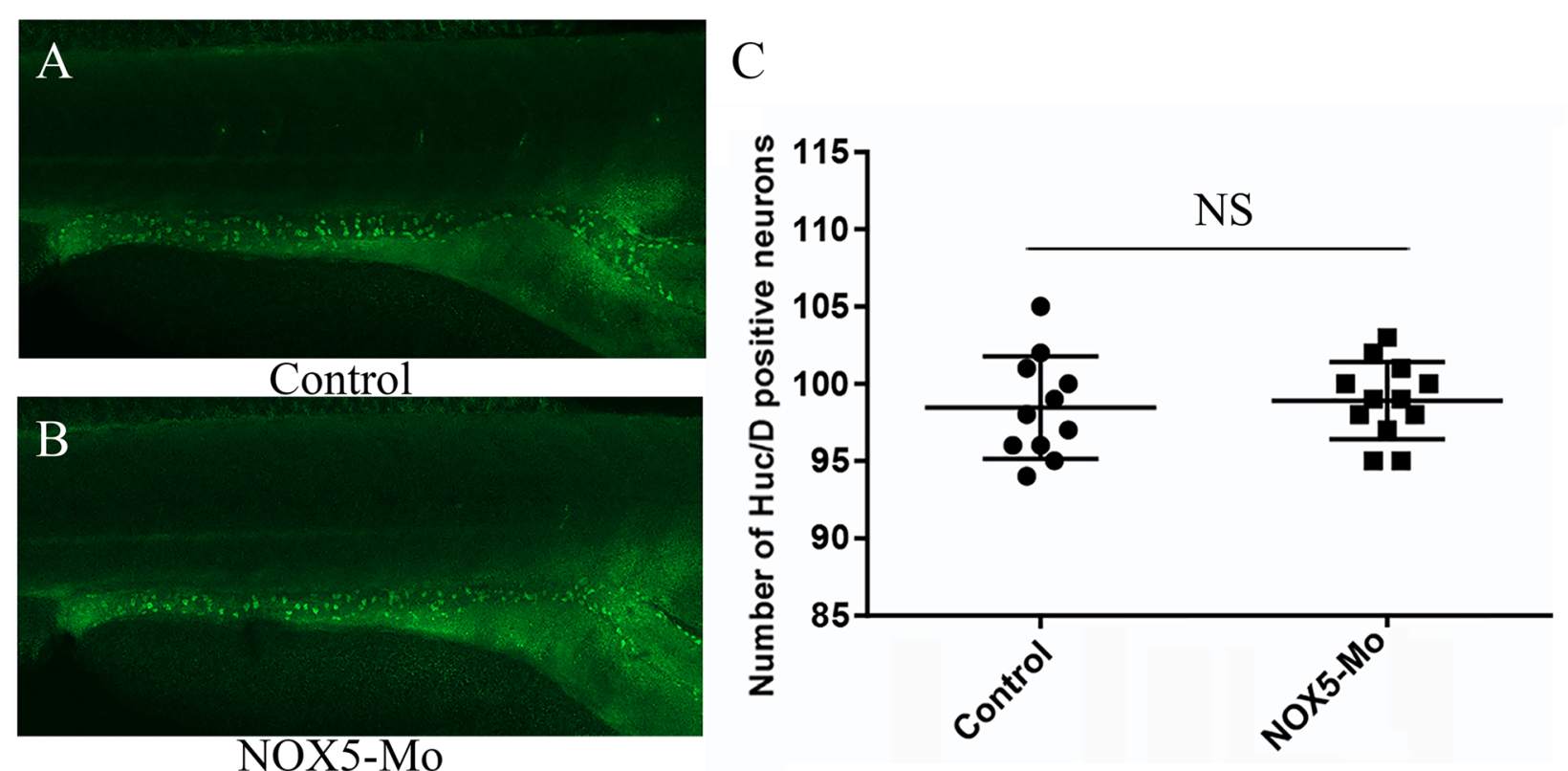

Fig. 6 Immunostaining with HuC/D at 5dpf show no difference between control group (a) and NOX5-MO group (b). No statistical difference in HuC/D+ neuron numbers between two groups (c)

pathophysiological significance of NOX5 remains unclear, but it seems to be important in the physiological regulation of sperm motility, vascular contraction and lymphocyte differentiation, and NOX5 hyper activation has been implicated in cardiovascular disease, kidney injury and cancer. One of the distinguishing features of NOX5 is the dependence on $\mathrm{Ca}^{2+}$ for its regulation [27]. Activation of NOX5 in response to elevated $\mathrm{Ca}^{2+}$ is a multi-phased process [28]. The amount of $\mathrm{Ca}^{2+}$ required to activate NOX5 fully is relatively high, and accordingly, additional systems involving regulatory proteins are operational that increase sensitivity to $\mathrm{Ca}^{2+}$, thereby facilitating ROS generation. Hence, NOX5 can be activated directly by $\mathrm{Ca}^{2+}$ or indirectly by interacting with other proteins and kinases, such as $\mathrm{Ca}^{2+}$-bound calmodulin or PKC [29]. Intriguingly, NOX5 is the first and only NADP $\mathrm{H}$ oxidase to be crystallized, providing opportunities to design specific NOX5 inhibitors and activators, which is crucial for biomedical research and potentially for therapeutic utility [30].

We used zebrafish as the animal model to explore the function of NOX5. The result of spatiotemporal expression spectrum of NOX5 in zebrafish embryo indicated that NOX5 might play a role in the early development of zebrafish, which is similar to the previous study about the expression of NOX family in zebrafish [31]. However, after significant knockdown of the NOX5 expression, there were no difference of $\mathrm{HuC} / \mathrm{D}$ positive neuron numbers of the GI tract between the normal group and the NOX5 knockdown group, indicated that the development of ENS in zebrafish do not require the
NOX5. Besides, the results of GI transit assay suggested that the GI motility were not affected by the absence of NOX5 protein either. Generally, GI motility is controlled by enteric neural crest cells that form the ENS and undergo extensive migration from the caudal hindbrain to colonize the total GI tract $[32,33]$. The results of the in vivo study in zebrafish showed that the loss function of NOX5 did not cause the absence of enteric neuron in zebrafish, which is the most important characteristic of HSCR.

Interestingly, our data of IHC showed that NOX5 is indeed located on the enteric neuron membrane. qPCR, western blot showed that NOX5 is strongly expressed in the myenteric ganglionic cell in the proximal and normal segment of HSCR colon and hardly expressed in the distal segment of colon with the absence of ganglionic cell. Recent researches have revealed that several aberrant gene expressions were involved in the pathological processes of HSCR, including UBR4 [34]. UBR4, a ubiquitin ligase protein, has been showed to be a novel HSCR gene [6]. It was required for neurogenesis and played an important role in myofiber hypertrophy $[35,36]$. Therefore, NOX 5 might be the downstream factor of UBR4. Downregulation of UBR4 expression might impact the development of ENS which probably reduce the expression of NOX5. On the one hand, abnormal distribution of ICCs had been observed in the aganglionic segment colon of HSCR patients [1]. What' more, cell migration, contraction and proliferation cannot complete without $\mathrm{Ca} 2^{+}$-dependent processes, and this is particularly pertinent to NOX5, because NOX5 itself is regulated by 


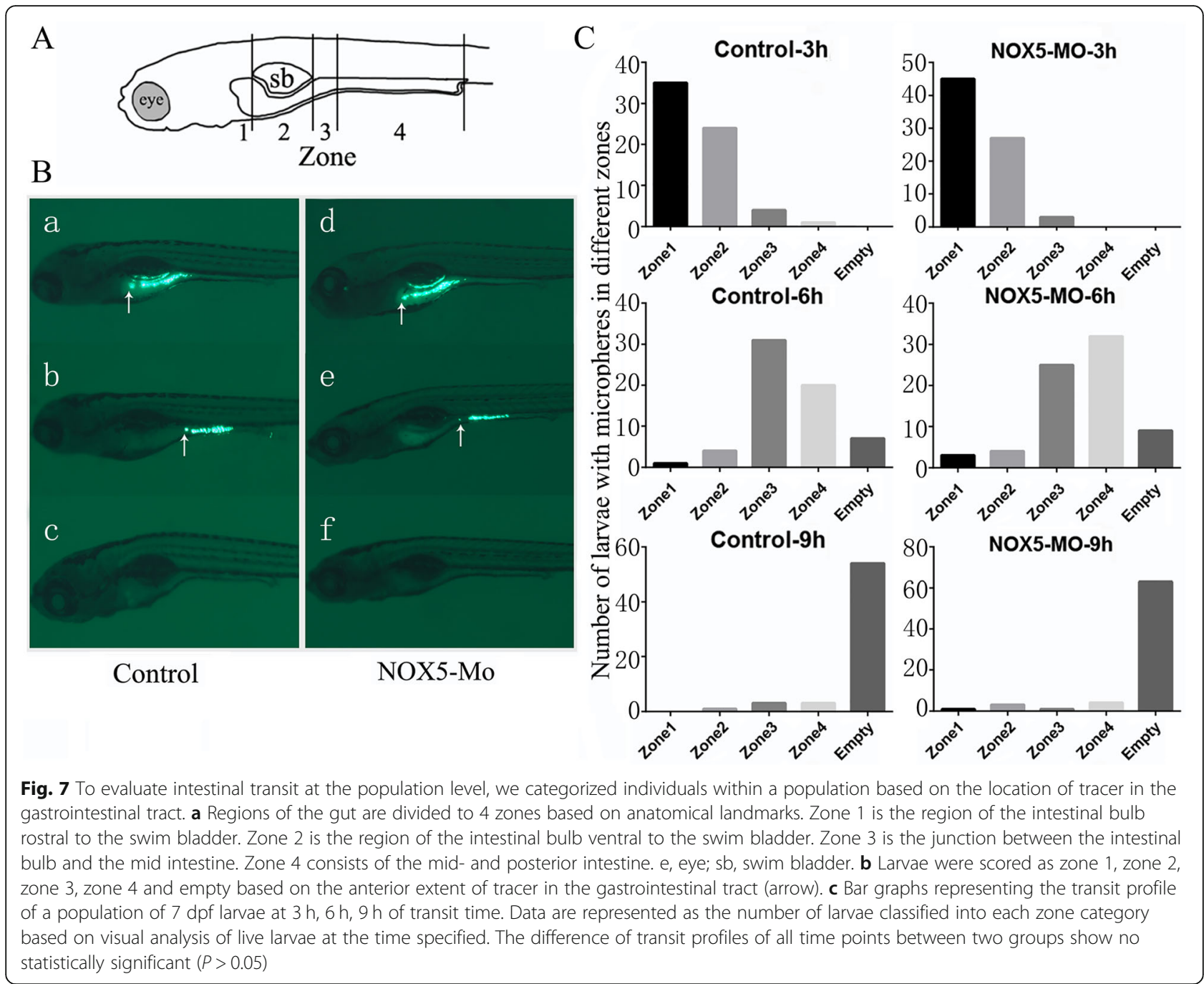

$\mathrm{Ca}^{+}$[37]. Moreover, in bowel motility, $\mathrm{Ca}^{+}$is regulated by ICCs, which are essential to generate and propagate the electrical cyclical activity (slow waves) in the intestines. Therefore, we hypothesize that the aberrant expression of NOX5 in aganglionic segment may occur due to the abnormal release of $\mathrm{Ca}_{2}^{+}$. More importantly, our study demonstrated that NOX5 expresses in the ganglionic cells specifically in colon tissue. NOX5 may serve as a typical neuron marker for enteric ganglionic cell to determine the occurrence and development of HSCR. It is noteworthy that the disruption of the balance between $\mathrm{Ca}_{2}^{+}$and NOX5 may lead to further deterioration of spasm in distal segment of HSCR patients. Potentially, abnormal release of $\mathrm{Ca}_{2}{ }^{+}$may result in the decreased expression of NOX5 through an unknown mechanism, which may further cause dysregulation of $\mathrm{Ca}^{+}$the concentration.

However, the association between $\mathrm{NOX} 5$ and $\mathrm{Ca}_{2}^{+}$ remain unclear and further studies are required to explain the decreased level of NOX5 in the aganglionic segment colon of HSCR patients.

\section{Conclusions}

Our study shows that NOX5 markedly decreased in the aganglionic segment of HSCR but didn't involve in the ENS development of zebrafish. It implies that absence of intestinal ganglion cells may lead to down-regulation of NOX5.

\section{Abbreviations \\ HSCR: Hirschsprung Disease; Gl: gastrointestinal; NOX5: NADPH oxidase 5; ENS: enteric nervous system; MO: Morpholino}

\section{Supplementary Information}

The online version contains supplementary material available at https://doi. org/10.1186/s12887-021-02611-5.

Additional file 1. Western blot was performed to validate the knockdown efficiency of the NOX5-MO. The results display a satisfactory knockdown power of the NOX5-MO used in our experiment. Protein in Mismatch NOX5 and Control group come from the protein mixture of 1 , 3, $5 \mathrm{dpf}$ in each group. 


\section{Acknowledgements}

This work was supported by the National Key Research and Development Program of China (2016YFE0203900). We gratefully appreciate the support of Bo Xiong and Jiexiong Feng for interpreting the data and revising the manuscript.

\section{Authors' contributions}

JW and JX carried out all experiments, acquired and interpreted the data, and wrote the manuscript. XFC and XYM breeding the zebrafish. DDZS and YJC collected the human colon samples. JXF and BX conceived of the study, acquired and interpreted the data, and obtained funding for the studies presented. All authors read and approved the final manuscript.

\section{Funding}

This work was supported by the National Key Research and Development Program of China (2016YFE0203900) and the Sanming Project of Medicine in Shenzhen (SZSM201812055). The funder "Jiexiong Feng" provided the experiment funds of this research and interpreted the data and revised the manuscript.

\section{Availability of data and materials}

The datasets generated or analyzed in this study were available from the corresponding authors on reasonable request.

\section{Declarations}

\section{Ethics approval and consent to participate}

The Institutional Review Board of Tongji Hospital, Tongji Medical College, Huazhong University of Science and Technology approved the protocol of the study (The ethical approval number: 2019-HP0761). All procedures performed in studies involving human participants were in accordance with the ethical standards of the institutional and/or national research committee and with the 1964 Helsinki declaration and its later amendments or comparable ethical standards. The informed written consents were obtained from the patients or patients' guardian.

\section{Consent for publication}

Not applicable.

\section{Competing interests}

The authors declare that they have no conflict of interest.

\section{Received: 7 August 2020 Accepted: 11 March 2021}

\section{Published online: 30 March 2021}

\section{References}

1. Chen X, Zhang H, Li N, Feng J. Pathological changes of interstitial cells of Cajal and ganglion cells in the segment of resected bowel in Hirschsprung's disease. Pediatr Surg Int. 2016;32(11):1019-24. https://doi.org/10.1007/s003 83-016-3961-7.

2. $\quad$ Langer JC. Hirschsprung disease. Curr Opin Pediatr. 2013;25(3):368-74. https://doi.org/10.1097/MOP.0b013e328360c2a0.

3. Jiao C, Yu D, Li D, Wang G, Feng J. A long-term follow-up of a new surgery method: laparoscope-assisted heart-shaped anastomosis for Hirschsprung's disease. J Laparoendosc Adv Surg Tech Part A. 2018;28(4):471-5. https://doi. org/10.1089/lap.2017.0275.

4. Luzon-Toro B, Villalba-Benito L, Torroglosa A, Fernandez RM, Antinolo G, Borrego S. What is new about the genetic background of Hirschsprung disease? Clin Genetics. 2020;97(1):114-24.

5. Gui H, Schriemer D, Cheng WW, Chauhan RK, Antinolo G, Berrios C, et al. Whole exome sequencing coupled with unbiased functional analysis reveals new Hirschsprung disease genes. Genome Biol. 2017;18(1):48. https://doi. org/10.1186/s13059-017-1174-6

6. Tilghman JM, Ling AY, Turner TN, Sosa MX, Krumm N, Chatterjee S, Kapoor A, Coe BP, Nguyen KDH, Gupta N, Gabriel S, Eichler EE, Berrios C, Chakravarti A. Molecular genetic anatomy and risk profile of Hirschsprung's disease. $\mathrm{N}$ Engl J Med. 2019;380(15):1421-32. https://doi.org/10.1056/NEJMoa1706594.

7. Gunadi KAS, Budi NYP, Hafiq HM, Maharani A, Febrianti M, et al. Aberrant Expressions and Variant Screening of SEMA3D in Indonesian Hirschsprung Patients. Front Pediatr. 2020;8:60.
8. Jiang Q, Arnold S, Heanue T, Kilambi KP, Doan B, Kapoor A, Ling AY, Sosa MX, Guy M, Jiang Q, Burzynski G, West K, Bessling S, Griseri P, Amiel J, Fernandez RM, Verheij JBGM, Hofstra RMW, Borrego S, Lyonnet S, Ceccherini I, Gray JJ, Pachnis V, McCallion AS, Chakravarti A. Functional loss of semaphorin $3 \mathrm{C}$ and/or semaphorin $3 \mathrm{D}$ and their epistatic interaction with ret are critical to Hirschsprung disease liability. Am J Hum Genet. 2015;96(4): 581-96. https://doi.org/10.1016/j.ajhg.2015.02.014.

9. Gunadi, Makhmudi A, Agustriani N, Rochadi. Effects of SEMA3 polymorphisms in Hirschsprung disease patients. Pediatr Surg Int. 2016; 32(11):1025-8. https://doi.org/10.1007/s00383-016-3953-7.

10. Garcia-Barcelo MM, Tang CS, Ngan ES, Lui VC, Chen Y, So MT, Leon TYY, Miao XP, Shum CKY, Liu FQ, Yeung MY, Yuan ZW, Guo WH, Liu L, Sun XB, Huang LM, Tou JF, Song YQ, Chan D, Cheung KMC, Wong KKY, Cherny SS, Sham PC, Tam PKH. Genome-wide association study identifies NRG1 as a susceptibility locus for Hirschsprung's disease. Proc Natl Acad Sci U S A. 2009;106(8):2694-9. https://doi.org/10.1073/pnas.0809630105.

11. Tang CS, Cheng G, So MT, Yip BH, Miao XP, Wong EH, et al. Genome-wide copy number analysis uncovers a new HSCR gene: NRG3. PLoS Genet. 2012; 8(5):e1002687. https://doi.org/10.1371/journal.pgen.1002687.

12. Kim JH, Cheong HS, Sul JH, Seo JM, Kim DY, Oh JT, Park KW, Kim HY, Jung SM, Jung K, Cho MJ, Bae JS, Shin HD. A genome-wide association study identifies potential susceptibility loci for Hirschsprung disease. PLoS One. 2014;9(10):e110292. https://doi.org/10.1371/journal.pone.0110292.

13. Shin JG, Seo JY, Seo JM, Kim DY, Oh JT, Park KW, Kim HY, Kim JH, Shin HD. Association analysis of NOX5 polymorphisms with Hirschsprung disease. J Pediatr Surg. 2019;54(9):1815-9. https://doi.org/10.1016/j. jpedsurg.2018.12.017.

14. Bedard K, Krause KH. The NOX family of ROS-generating NADPH oxidases: physiology and pathophysiology. Physiol Rev. 2007;87(1):245-313. https:// doi.org/10.1152/physrev.00044.2005.

15. Hurd TR, DeGennaro M, Lehmann R. Redox regulation of cell migration and adhesion. Trends Cell Biol. 2012;22(2):107-15. https://doi.org/10.1016/j.tcb.2 011.11.002.

16. Schulz E, Munzel T. NOX5, a new "radical" player in human atherosclerosis? J Am Coll Cardiol. 2008;52(22):1810-2. https://doi.org/1 0.1016/j.jacc.2008.08.040

17. Datla SR, Griendling KK. Reactive oxygen species, NADPH oxidases, and hypertension. Hypertension (Dallas, Tex : 1979). 2010;56(3):325-30.

18. Bedard $\mathrm{K}$, Jaquet $\mathrm{V}$, Krause KH. NOX5: from basic biology to signaling and disease. Free Radic Biol Med. 2012;52(4):725-34. https://doi.org/10.1016/j. freeradbiomed.2011.11.023.

19. Wei J, Li N, Xia X, Chen X, Peng F, Besner GE, Feng J. Effects of lipopolysaccharide-induced inflammation on the interstitial cells of Cajal. Cell Tissue Res. 2014;356(1):29-37. https://doi.org/10.1007/s00441-013-1 775-7.

20. MW. The zebrafish book. A guide for the laboratory use of zebrafish (Danio rerio). Eugene, OR: University of Oregon Press; 2000.

21. Balasubramanian S, Raghunath A, Perumal E. Role of epigenetics in zebrafish development. Gene. 2019;718:144049. https://doi.org/10.1016/j.gene.201 9.144049.

22. Thisse C, Thisse B. High-resolution in situ hybridization to whole-mount zebrafish embryos. Nat Protoc. 2008;3(1):59-69. https://doi.org/10.1038/ nprot.2007.514.

23. Stainier DYR, Raz E, Lawson ND, Ekker SC, Burdine RD, Eisen JS, Ingham PW, Schulte-Merker S, Yelon D, Weinstein BM, Mullins MC, Wilson SW, Ramakrishnan L, Amacher SL, Neuhauss SCF, Meng A, Mochizuki N, Panula P, Moens CB. Guidelines for morpholino use in zebrafish. PLoS Genet. 2017; 13(10):e1007000. https://doi.org/10.1371/journal.pgen.1007000.

24. Field HA, Kelley KA, Martell L, Goldstein AM, Serluca FC. Analysis of gastrointestinal physiology using a novel intestinal transit assay in zebrafish. Neurogastroenterol Motility. 2009;21(3):304-12. https://doi.org/10.1111/j.13 65-2982.2008.01234.x.

25. Bahrami A, Joodi M, Moetamani-Ahmadi M, Maftouh M, Hassanian SM, Ferns GA, Avan A. Genetic background of Hirschsprung disease: a bridge between basic science and clinical application. J Cell Biochem. 2018;119(1): 28-33. https://doi.org/10.1002/jcb.26149.

26. Touyz RM, Anagnostopoulou A, Rios F, Montezano AC, Camargo LL. NOX5: molecular biology and pathophysiology. Exp Physiol. 2019;104(5):605-16. https://doi.org/10.1113/EP086204.

27. Zhao GJ, Zhao CL, Ouyang S, Deng KQ, Zhu L, Montezano AC, Zhang C, Hu F, Zhu XY, Tian S, Liu X, Ji YX, Zhang P, Zhang XJ, She ZG, Touyz RM, Li H. 
Ca (2+)-dependent NOX5 (NADPH oxidase 5) exaggerates cardiac hypertrophy through reactive oxygen species production. Hypertension. 2020;76(3):827-38. https://doi.org/10.1161/HYPERTENSIONAHA.120.15558.

28. Tirone F, Radu L, Craescu CT, Cox JA. Identification of the binding site for the regulatory calcium-binding domain in the catalytic domain of NOX5. Biochemistry. 2010;49(4):761-71. https://doi.org/10.1021/bi901846y.

29. Wei CC, Reynolds N, Palka C, Wetherell K, Boyle T, Yang YP, Wang ZQ Stuehr DJ. Characterization of the 1st and 2nd EF-hands of NADPH oxidase 5 by fluorescence, isothermal titration calorimetry, and circular dichroism. Chem Central J. 2012;6(1):29. https://doi.org/10.1186/1752-153X-6-29.

30. Magnani F, Nenci S, Millana Fananas E, Ceccon M, Romero E, Fraaije MW, et al. Crystal structures and atomic model of NADPH oxidase. Proc Natl Acad Sci U S A. 2017;114(26):6764-9.

31. Weaver CJ, Leung YF, Suter DM. Expression dynamics of NADPH oxidases during early zebrafish development. J Comp Neurol. 2016;524(10):2130-41. https://doi.org/10.1002/cne.23938.

32. Greenwood-Van Meerveld B, Johnson AC, Grundy D. Gastrointestinal physiology and function. Handb Exp Pharmacol. 2017;239:1-16. https://doi. org/10.1007/164_2016_118.

33. Spencer NJ, Hu H. Enteric nervous system: sensory transduction, neural circuits and gastrointestinal motility. Nat Rev Gastroenterol Hepatol. 2020; 17(6):338-51. https://doi.org/10.1038/s41575-020-0271-2.

34. Gunadi, Kalim AS, Liana E, Fauzi AR, Sirait DN, Afandy D, et al. Aberrant UBR4 expressions in Hirschsprung disease patients. BMC Pediatr. 2019; 19(1):493.

35. Kim ST, Lee YJ, Tasaki T, Hwang J, Kang MJ, Yi EC, Kim BY, Kwon YT. The Nrecognin UBR4 of the $\mathrm{N}$-end rule pathway is required for neurogenesis and homeostasis of cell surface proteins. PLoS One. 2018;13(8):e0202260. https:// doi.org/10.1371/journal.pone.0202260.

36. Hunt LC, Stover J, Haugen B, Shaw TI, Li Y, Pagala VR, et al. A Key Role for the Ubiquitin Ligase UBR4 in Myofiber Hypertrophy in Drosophila and Mice. Cell Rep. 2019;28(5):1268-81 e6.

37. Banfi B, Molnar G, Maturana A, Steger K, Hegedus B, Demaurex N, et al. A Ca (2+)-activated NADPH oxidase in testis, spleen, and lymph nodes. J Biol Chem. 2001;276(40):37594-601. https://doi.org/10.1074/jbc.M103034200.

\section{Publisher's Note}

Springer Nature remains neutral with regard to jurisdictional claims in published maps and institutional affiliations.

Ready to submit your research? Choose BMC and benefit from:

- fast, convenient online submission

- thorough peer review by experienced researchers in your field

- rapid publication on acceptance

- support for research data, including large and complex data types

- gold Open Access which fosters wider collaboration and increased citations

- maximum visibility for your research: over $100 \mathrm{M}$ website views per year

At $\mathrm{BMC}$, research is always in progress.

Learn more biomedcentral.com/submissions 